\title{
IrRECIST Non-Evaluable
}

National Cancer Institute

\section{Source}

National Cancer Institute. irRECIST Non-Evaluable. NCI Thesaurus. Code C140320.

Used in exceptional cases where insufficient data exists. 